\title{
Transcultural study on quality of life in patients diagnosed of schizophrenia from Mexico and Spain
}

\author{
Adolfo Jarne Esparcia ${ }^{1}$, Teresita Villaseñor Cabrera ${ }^{2}$, Joan Guàrdia Olmos ${ }^{1}$, \\ Mónica Arroyo Medrano ${ }^{2}$, Maribel Peró Cebollero ${ }^{1}$ \\ ${ }^{1}$ Facultat de Psicologia. Universitat de Barcelona. Institut de Recerca en Cervell, Cognició i Conducta (IR3C) (Spain); \\ ${ }^{2}$ Departamento de Neurociencias. Centro Universitario de Ciencias de la Salud. Universidad de Guadalajara (México). Hospital \\ Civil de Guadalajara
}

Disponible online 30 de agosto de 2009

\begin{abstract}
The aim of this paper was to evaluate the differences between two samples of schizophrenic patients from two different cultural contexts. Matched by age and gender, each 40 -subject sample includes patients with differential diagnosis of schizophrenia. One sample was taken from the Barcelona Hospital network (Spain) and the other one from the Hospital Civil Universitario of Guadalajara (Mexico). Several demographic and clinical variables were evaluated and the Health Related Quality of Life Scale (HRQLS) was conducted on all the subjects. The HRQLS was adapted to Spanish (Rodriguez, et al., 1995). The results confirmed the factor structure studied and they showed no special differences in the total score of the HRQLS. However, an important effect was found when analyzing the results separately for the three factors: Interpersonal Relationship (IR1), Instrumental Resources (IR2) and Intrapsychic Foundation (IF), or in the items of the Intrapsychic Foundations factor. Given these differences, it is considered that these scales can be used to carry out an exhaustive profile analysis in order to organize a personalized treatment, in comparison to the total score of the HRQLS.
\end{abstract}

Keywords:

HRQLS, Schizophrenia, Factor analysis, Quality of life.

El objetivo de este trabajo fue evaluar las diferencias entre dos muestras de pacientes diagnosticados de esquizofrenia, de dos contextos culturales distintos. Ambas muestras estuvieron constituidas por 40 sujetos, emparejados por edad y género, diagnosticados de distintas formas de esquizofrenia. Una muestra se obtuvo de la red hospitalaria de Barcelona (España) y la otra del Hospital Civil Universitario de Guadalajara (Méjico). Diversas variables demográficas y clínicas fueron medidas en todos los sujetos, además de administrarles la Escala de Calidad de Vida en Salud (HRQLS) en su adaptación a población hispana (Rodríguez, et al., 1995). Los resultados obtenidos confirmaron la estructura factorial de la escala sin mostrar diferencias significativas entre ambos grupos en la puntuación total de HRQLS. Sin embargo, un efecto importante se encontró al analizar los resultados de cada uno de los tres factores por separado: Relación Interpersonal (IR1), Recursos Instrumentales (IR2) y Fundamentos Intrapsíquicos (IF), en especial en los valores del factor de Fundamentos Intrapsíquicos. A la vista de estos resultados, se considera que las tres subescalas, no así la puntuación total, resultan adecuadas para el estudio de los perfiles de los sujetos de cada muestra al objeto de organizar tratamientos más contextualizados.

Palabras clave:

HRQLS, Esquizofrenia, Análisis Factorial, Calidad de Vida.

Correspondence concerning this article should be addressed to Joan Guàrdia Olmos. Department of Methodology of Behavioural Science. Faculty of Psychology. Passeig de la Vall d’Hebrón, 171, 08035, Barcelona. Spain. Phone: (+34) 9331250 90. Fax: (+34) 9340213 59. E-mail: jguardia@ub.edu 
In recent years, quality-of-life measurements have been widely used to evaluate the clinical state and therapeutic process in patients with mental disorders. By definition, quality of life concerns the limitations faced by the patients as a result of their pathology, and therefore, a number of treatments now include the notion of improved living standards (Grant, 2000; Pol, Neipp \& Rodríguez, 2000) alongside symptomatic amelioration. Indeed, the literature on both schizophrenia and severe mental illness in general now includes numerous papers about normalization and quality of life promotion among these patients. Therefore, evaluating quality of life in schizophrenic patients has become an issue of scientific concern, and in this regard, the development of the Health Related Quality of Life Scale (HRQLS) (Carperter, 1984) was a turning point in the traditional measurement of this concept. Its use has since spread and it has served as an indicator in several evaluations and diagnoses, as well as being a sensitive indicator of therapeutic effects in a wide range of reports (Beasley et al., 2006; Bellack, Morrison, Wixted \& Mueser, 1990; Bow, Velligan, Millar \& Olsen, 1999; Phillips, Van Brunt, Roychowdhury, Xu \& Naber, 2006). Likewise, there is evidence to suggest that the HRQLS is a sensitive tool for evaluating the effects of psychological and social interventions in this kind of patient. Cardoso, Bandeira, Caiaffa \& Fonseca (2002) reported evidence of improved quality of life in schizophrenic patients involved in specific rehabilitation programmes, while Hofstetter, Lysacker \& Mayeda (2005) evaluated the circadian cycle effects associated with quality of life in these patients.

The HRQLS has also been used as a sensitive indicator in studying the evolution of schizophrenia (Barcia, Morcillo \& Borgoñós, 1995; Morcillo, Barcia \& Borgoñós, 1995) and its clinical and syndrome forms (Baca et al., 2008; Browne, 1999; Gourevitch, Abbadi \& Guelfi, 2004; Mínguez, González, Alonso, Sanguino \& García, 2005; Möller, 2006); several reports have even combined the evaluation of impaired cognitive functions (from neuropsychological studies) with complementary measurements of quality of life (González, Alonso, Mínguez \& Sanguino, 2004). Thus, as Cramer et al. (2000) argue, it is clearly important to consider the relationship between illness and quality of life in any strict approach to the study of schizophrenia. Essentially, establishing HRQLS as a quality of life measure in mental illness has become usual and indispensable in studies which regard the patients' quality of life as an inevitable focus of clinical attention. However, the psychometric basis of the HRQLS remains an issue of debate because of its properties as a standardized scale and it being unconnected to typical biases and errors for psychological measurements. A number of reports have proposed various ready reckoners and normalizations of the scale, and several points of view have been adopted as regards its conceptualization. For example, Cardoso et al. (2003) or Ching \& Wan (2006) used classical test theory in their standardization of a Brazilian population, in a similar way to the approach taken in an earlier report by Scott et al. (2006). Other approaches have been more clinical than psychometric, for example, the French standardization carried out by Whitty et al. (2004) or the German one by Franz et al. (1998). These studies are based on criteria with a greater clinical significance and sought commonalities between statistical and clinical significance from confidence intervals, as in the methodological study by Lehman, Postrado \& Rachuba (1993).

In addition, there are sufficient data regarding the reliability and validity (Mínguez et al., 2005) of the HRQLS to suggest that it is a sensitive and specific instrument for evaluating quality of life levels in schizophrenic patients; furthermore, its sensitivity compared to other tests from the World Health Organization (WHO) (Simon, Guelfi \& Ginestest, 1999) has also been reported. Therefore, using the HRQLS as an objective measurement of quality of life seems a better choice than other similar tests with subjective criteria and which lack a sound psychometric basis.

A further point to make is that quality of life is clearly linked to transcultural issues in terms of differences in welfare levels across the planet and the underlying subjective aspect of quality of life, a concept which is obviously influenced by cultural conceptions. Therefore, knowledge about transcultural differences in quality of life can help develop a better understanding of the mental illness and the planning of specific intervention policies for each region or group (Borgoñós, Morcillo \& Barcia, 1995; Cardoso, et al., 2002; Bryson, Lysaker \& Bell, 2002; Kartsona \& Hilari, 2006).

Besides everything described above, HRQLS has been used by means of scales and normalizations in non-Hispanic populations, and the works which include the recommendations of the scaling studies of the Spanish adaptation are scarce (Rodriguez, et al., 1995), which makes it especially interesting to submit the aforementioned scale to its verification, both internal and clinical, in populations of mentally ill patients.

In this context, the present study aims to report the clinical features revealed by the HRQLS data in two samples of schizophrenic patients from different cultural milieus in which the same language is spoken. We also analyzed the biases and differences produced by this variable in quality of life evaluations and measurements derived from the HRQLS; since the cultural conditions vary between the Mexican and Spanish samples, this aspect should be empirically evaluated in order to correct any bias produced. Complementarily and according to the possibilities of the sample size, we will try to analyze to which extent the factor structure proposed by Scott et al. (2006) is confirmed.

\section{Method}

\section{Participants}

Two groups, each comprising 40 schizophrenic patients (according to DSM-IV-R), were enrolled: one group was recruited from the Hospital Civil of Guadalajara (Mexico) and 
the other, from the network of psychiatric hospitals in Barcelona (Spain). The inclusion and exclusion criteria were the following: patients not in acute phase of schizophrenia, outpatient treatment, clinical history of fewer than six months of hospitalization, no other concomitant mental pathology, clear monitoring of treatment and follow-up, regular presence of relatives or health care workers, and a pathological evolution which enabled the patients to answer the complementary semistructured interview which is part of the HRQLS.

Both samples included 20 male and 20 female patients because there are some reports of differences between men and women (Baca et al., 2008). Age-matching of samples was applied and so the two samples were similar in average age (for Mexican sample mean = 34.60; SD = 13.474; and for Spanish sample mean $=31.90 ; \mathrm{SD}=11.810)$. The subjects gave their voluntary informed consent to participate and received all the necessary information regarding the study. Sociodemographic descriptive statistics for both samples are shown in Table 1.

Table 1. Descriptive statistics (percentage) for the marital status, job and diagnostic variables.

\begin{tabular}{lcc}
\hline Category & Mexico & Spain \\
\hline Single & 52.50 & 77.50 \\
Married & 37.50 & 10.00 \\
Widowed or divorcee & 10.00 & 12.50 \\
& & \\
Student & 33.75 & 10.00 \\
Some paid or unpaid work & 0.00 & 40.00 \\
Unemployed & 66.25 & 50.00 \\
& & \\
Disorganized type schizophrenia & 70.00 & 20.00 \\
Catatonic type schizophrenia & 30.00 & 0.00 \\
Paranoid type schizophrenia & 0.00 & 40.00 \\
Undifferentiated or residual type schizophrenia & 0.00 & 40.00 \\
\hline
\end{tabular}

As mentioned above, matching was applied to the age variable and so the two groups did not differ in terms of age, gender or marital status. Descriptive statistics did reveal some differences in the occupational situation $\left(\chi^{2}=16.484, p<.001\right)$ : in the Spanish sample, the subjects tended to work even if in an unpaid capacity, whereas the Mexican sample did not generally undertake any activity. Similar differences were observed for the type of schizophrenia diagnosed $\left(\chi^{2}=41.333, \mathrm{p}<.001\right)$, with the prevalence of paranoid and undifferentiated/residual type schizophrenia being higher in the Spanish than in the Mexican sample, where the prevailing diagnosis was disorganized type schizophrenia. A possible explanation of these differences could be that, in the first case, to cultural differences, while in the second; they result from variations in the clinical protocols used at the sampling centres. These results will have to be taken into account in the subsequent analysis to control their possible effect on the comparisons between samples in order to prevent the effect of both the labor situation and the type of schizophrenia, since the degree of severity was not the same in both samples (Kendall \& Sheldrick, 2000).

\section{Instruments}

An initial protocol of demographic and life data (sex, age, marital status, occupational situation and type of schizophrenia) was applied to each group of subjects and was used to characterize both samples. In addition, at the time of recruitment the HRQLS (Heinrichs et al., 1984) was administered in its Spanish adaptation (Rodriguez et al., 1995). The same adaptation was used with the Mexican sample, as we considered it to be linguistically and semantically close enough to Mexican Spanish. However, some items were adapted to make them more understandable for Mexican subjects; this adaptation was carried out after a brief pilot trial to evaluate it and the Mexican version thus showed slight changes compared to the Spanish one, with no important modifications of the scale's psychometric properties.

The original version and its adaptation to Spanish comprise a 21 -item scale with an ordinal response scale between 0 and 6 , with which the clinic (heteroadministration) determines the degrees of conservation of each of the 21 aspects approached in the questionnaire. The assessment data from the original version (Heinrichs et al. 1984) showed significant internal consistency estimated by means of Cronbach's alpha $(\alpha=.94)$ and high construct validity by means of a Factor Analysis that showed a total explained variance of $74 \%$. This factor structure was later accounted for by means of a Confirmatory Factor Analysis (Scott et al., 2006), thus obtaining enough evidence of the aforementioned structure $\left(\chi^{2}=13.74, \mathrm{p}=.45\right.$ and Goodnes of Fit Index (GFI $=.96)$. The HRQLS evaluates three factors(following the factorial structure of Scott et al.; 2006): (1) Intrapsychic foundations: it evaluates the conation, cognition and affectivity dimensions which are important in the schizophrenia deficit; (2) Interpersonal relationships: it evaluates the schizophrenic's social capacity and his/her capacity to get close to somebody; and (3) Instrumental resources: it evaluates the patient's good functioning as a student, worker, housewife, etc. and the satisfaction with his/her performance in these areas.

The Spanish version of HRQLS (Rodriguez et al., 1995) was built with scrupulous fidelity to the characteristics and structure of the original. The adaptation to Spanish was carried out according to the backtranslation system and to the discretion of clinical experts in mental illnesses. The data of this adaptation showed adjustment psychometrical indices of an equal level and intensity to the ones presented in the original version ( $\alpha$ de Cronbach $=.91$ and GFI $=.93$ ). Finally, in the two samples of our study, the psychometrical values were not in disagreement with those here presented, since internal consistency was $\alpha=.96$ for the Spanish sample and $\alpha=.94$ for the Mexican sample. For the construct validity, as in the original English version, proper adjustment values 
were obtained in both the Spanish and the Mexican sample, as will be commented subsequently (bearing in mind that the versions used in Spain and Mexico were different and acknowledging the methodological limitations derived from both sample sizes).

\section{Procedure}

The subjects were evaluated during the period from May 2004 to July 2006. The corresponding protocol and scale were administered to each sample by only one psychologist in each sample; the two evaluators received prior training at the same time in order to obtain a between-evaluator agreement coefficient of 0.96 as a trial prior to the final data collection.

\section{Data analysis}

All the analyses were carried out by SPSS 15.0 and EQS v. 6.1. (Bentler \& Wu, 1995). First of all, we carried out a descriptive analysis of the 21 HRQLS items. Given the small sample size, this descriptive study was used to establish the fundamental characteristics of the 21 reactives in order to assess to what extent the data analyzed could be sufficiently robust to be approached by Confirmatory Factor Analysis (CFA). We tried to compensate for the small sample size by strictly abiding by the conditions of application of the distributions observed (at least symmetrical distributions and absence of outliers) for a feasible estimation of the parameters of a measurement model (CFA) under the classical view of the Structural Equation Models, using the technique of least restrictive and robust estimation (Elliptical Least Square, ELS) (Guàrdia, 1986). Consequently, and given that none of the 21 distributions observed in each sample showed neither excessive asymmetry, nor high variability or extreme values, we chose to verify the structure of three factors proposed by Scott et al. (2006) by means of CFA (Interpersonal Relationship: items 6, 7, 8, 13, 14, 15, 16, 18, 19, 20 and 21, Instrumental Resources: items: 1, 2, 3, 4, 5, 6, 7 and 8; and Intrapsychic Foundations: items: 9, 10, 11, 12, 13, 15, 16 and 17).

Complementarily to what has been presented above, we considered a more conventional statistical approach which, besides establishing conclusions about the comparison between the Spanish and Mexican samples, made it possible to know the degree of effect which the different labor situation and type of diagnosis could generate in the possible differences between the two samples here considered. Given the categorical character of both variables (labor situation and type of schizophrenia), the use of a conventional Analysis of Covariance was not feasible, so we chose to analyze, initially, each of the 21 items according to the categories of the variables to be controlled ( 3 categories for the labor situation variable, and 4 for the type of diagnosis variable). Given the number of categories and the ordinal character of the HRQLS items, this effect was analyzed by means of Kruskal-Wallis Test $(\mathrm{H})$. No statistically significant difference was obtained from these analyses, which made it possible to establish the scarce interfering effect that the labor situation or the type of diagnosis could cause on the fundamental analysis which focused on the study of the behavior of each item, each factor, and the total of the scale between the two samples considered. (This analysis presented degrees of signification comprised between .12 and .86, in any case, clearly nonsignificant. Special attention must be paid to the boxes with 0 samplings, since Mann-Whitney U test and Kruskal-Wallis test had to be combined.

For the comparisons between the two samples of each item, we used Mann-Whitney $U$ test for two independent groups (given its ordinal character), and in the case of factor scores and scale total value, $t$-test for independent groups. The values for each factor were obtained from the summation of each of the values that constitute it (structure proposed by Scott et al., 2006), and for the scale total, the summation of the 21 items of the scale was established. We would like to clarify, finally, that we did not choose to use the statistical tests typical of paired groups because the pairing variables were not used in any analysis, since they were considered to be controlled and, therefore, the primary variance maximized for each contrast, we used a $95 \%$ confidence level, corrected by the Bonferroni method to reduce the type I error rate.

\section{Results}

The measure of fit from the confirmatory factor analysis confirmed the factor structure proposed by Scott et al. (2006) in both samples and, in the case of the Spanish group, a better fit was observed. Table 2 shows the results in both measurement models.

Table 2. Several fit indexes values in measurement models for Mexican and Spanish samples (Bentler \& Wu, 1995; Lee, 2006).

\begin{tabular}{lccccccc}
\hline Sample & GFI & AGFI & NFI & NNFI & RMSE & CFI & R $^{2}$ \\
\hline Mexican & .89 & .91 & .90 & .92 & .003 & .89 & .76 \\
Spanish & .90 & .91 & .94 & .94 & .0021 & .86 & .81 \\
\hline
\end{tabular}

Note: GFI: Goodness of Fit Index; AGFI: Adjusted of Fit Index; NFI: Bentler and Bonnet Normed Fit Index; NNFI: Bentler and Bonnet Non Normed Fit Index; CFI: Comparative Fit Index; $\mathrm{R}^{2}$ : Determination Coefficient). It's impossible to analyze the fit through $\chi^{2}$ due the singular character of covariance initial matrix.

Therefore, having confirmed the measurement structure, we then obtained the standardized values for each subject (both samples) for each of the three factors, as well as for the scale's total score derived from the sum of all the items' scores. Descriptive statistics and contrasts derived to compare both samples are shown in Tables 3, for Mann-Whitney U test; and Table 4 , for t-test. 
Table 3. Descriptive values (mean and standard deviation), statistical contrasts for the HRQLS items from Spanish and Mexican samples (38 degree of freedom for all statistical analysis).

\begin{tabular}{|c|c|c|c|c|}
\hline Variable & $\begin{array}{c}\text { Mexican } \\
\text { Sample }\end{array}$ & $\begin{array}{l}\text { Spanish } \\
\text { Sample }\end{array}$ & U-test & Significance \\
\hline 1. Family Relationships & $\begin{array}{c}3.4 \\
(2.111)\end{array}$ & $\begin{array}{c}3.30 \\
(1.418)\end{array}$ & 44 & .68 \\
\hline 2. Intimacy & $\begin{array}{c}1.87 \\
(1.889)\end{array}$ & $\begin{array}{c}1.97 \\
(1.564)\end{array}$ & 32 & .72 \\
\hline 3. Activities with acquaintances & $\begin{array}{c}1.67 \\
(1.749)\end{array}$ & $\begin{array}{c}2.20 \\
(1.584)\end{array}$ & 26 & .68 \\
\hline 4. Social Activities & $\begin{array}{c}1.53 \\
(1.795)\end{array}$ & $\begin{array}{c}2.23 \\
(1.382)\end{array}$ & 315 & $.04 *$ \\
\hline 5. Social Role & $\begin{array}{c}2.33 \\
(1.668)\end{array}$ & $\begin{array}{c}2.53 \\
(1.252)\end{array}$ & 53 & .75 \\
\hline 6. Initiative & $\begin{array}{c}1.87 \\
(1.655)\end{array}$ & $\begin{array}{c}1.70 \\
(1.317)\end{array}$ & 45 & .64 \\
\hline 7. Reticence & $\begin{array}{c}2.33 \\
(1.749)\end{array}$ & $\begin{array}{c}2.60 \\
(1.303)\end{array}$ & 21 & .71 \\
\hline 8. Socio-sexual Relationship & $\begin{array}{c}2.57 \\
(2.096)\end{array}$ & $\begin{array}{c}1.87 \\
(1.432)\end{array}$ & 22 & .64 \\
\hline 9. Occupation & $\begin{array}{c}2.93 \\
(2.083)\end{array}$ & $\begin{array}{c}1.80 \\
(1.730)\end{array}$ & 311 & $.033^{*}$ \\
\hline 10. Realization & $\begin{array}{c}2.87 \\
(2.013)\end{array}$ & $\begin{array}{c}1.57 \\
(1.331)\end{array}$ & 273 & $.007 * *$ \\
\hline 11. Performance & $\begin{array}{c}3.40 \\
(2.238)\end{array}$ & $\begin{array}{c}1.60 \\
(1.276)\end{array}$ & 240 & $.001 * *$ \\
\hline 12. Satisfaction & $\begin{array}{c}4.80 \\
(1.033)\end{array}$ & $\begin{array}{c}3.27 \\
(1.100)\end{array}$ & 230 & $.002 * *$ \\
\hline 13. Resolution & $\begin{array}{c}2.13 \\
(2.097)\end{array}$ & $\begin{array}{c}2.03 \\
(1.520)\end{array}$ & 38 & .76 \\
\hline 14. Motivation & $\begin{array}{c}2.47 \\
(1.943)\end{array}$ & $\begin{array}{c}2.63 \\
(1.245)\end{array}$ & 28 & .62 \\
\hline 15. Curiosity & $\begin{array}{c}1.47 \\
(1.737)\end{array}$ & $\begin{array}{c}2.47 \\
(1.042)\end{array}$ & 242 & $.001 * *$ \\
\hline 16. Anhedonia & $\begin{array}{c}2.53 \\
(1.655)\end{array}$ & $\begin{array}{c}2.43 \\
(1.040)\end{array}$ & 44 & .76 \\
\hline 17. Time use & $\begin{array}{c}3.33 \\
(1.680)\end{array}$ & $\begin{array}{c}1.67 \\
(1.647)\end{array}$ & 237 & $.001 * *$ \\
\hline 18. Object use & $\begin{array}{c}4,07 \\
(1,856)\end{array}$ & $\begin{array}{c}3.50 \\
(1.253)\end{array}$ & 342 & $.001 * *$ \\
\hline 19. Daily Activities & $\begin{array}{c}3.27 \\
(1.999)\end{array}$ & $\begin{array}{c}3.27 \\
(1.363)\end{array}$ & 53 & .73 \\
\hline 20. Empathy & $\begin{array}{c}3.33 \\
(1.685)\end{array}$ & $\begin{array}{c}2.97 \\
(1.245)\end{array}$ & 36 & .69 \\
\hline 21. Interviewer Interaction & $\begin{array}{c}4.47 \\
(2.080) \\
\end{array}$ & $\begin{array}{c}3.20 \\
(1.243) \\
\end{array}$ & 236 & $.001 * *$ \\
\hline
\end{tabular}

$* \mathrm{p}<.05 * * \mathrm{p}<.01$

Table 4. Descriptive values (mean and standard deviation), statistical contrasts for the HRQLS factor scores and total score from Spanish and Mexican samples (38 degree of freedom for all statistical analysis).

\begin{tabular}{lcccc}
\hline Variable & $\begin{array}{c}\text { Mexican } \\
\text { Sample }\end{array}$ & $\begin{array}{c}\text { Spanish } \\
\text { Sample }\end{array}$ & t-test & Significance \\
\hline Interpersonal Relationships & 0.5501 & -0.3667 & \multirow{2}{*}{2.474} & $.021^{*}$ \\
& $(1.1964)$ & $(0.6586)$ & & \\
Instrumental Resources & -0.7873 & 0.5249 & \multirow{2}{*}{4.170} & $<.001^{* *}$ \\
& $(0.7127)$ & $(0.8061)$ & & \\
Intrapsychic Foundations & 0.4445 & -0.2963 & 2.131 & $.048^{*}$ \\
Total Score & $(1.2421)$ & $(0.6980)$ & & \\
& 68.80 & 62.666 & 1.127 & .41 \\
\hline
\end{tabular}

$* \mathrm{p}<.05 * * \mathrm{p}<.01$

In general, the significant differences (all of them with an effect size higher than $r=.62$ ) are concentrated in those items that comprise the Intrapsychic Foundations factor (items 9, 10, 11, 12, 15 and 17). In fact, six of the eight items that make up this factor showed significant differences, with higher values being found in the Mexican sample, for all of them except for item 15 (Curiosity), where the difference was in the opposite direction. Higher mean values were also found in the Mexican sample for two other items belonging to the Interpersonal Relationships factor (items 18 and 21), while item 4, which loads on the Instrumental Resources factor, showed the opposite effect, i.e. the observed mean was higher in the Spanish sample. However, in contrast to what is observed for the Intrapsychic Foundations factor, the small number of items yielding a significant contrast for the other two factors suggests that there are no particular differences between the two samples in this regard.

It is important to highlight the lack of any significant difference in the total score of the two samples, as well as the differences observed between factor scores. The above-mentioned results suggest that, in general, there is no particular difference in the total mean score of the two groups. However, this analysis is incomplete unless we also take into account the direction of differences obtained between factors in those cases where the two samples yield different results. Figure 1 shows the combined mean values of the three factors in each group.

Figure 1. Mean values for each group of the three factors in the HRQLS structure.

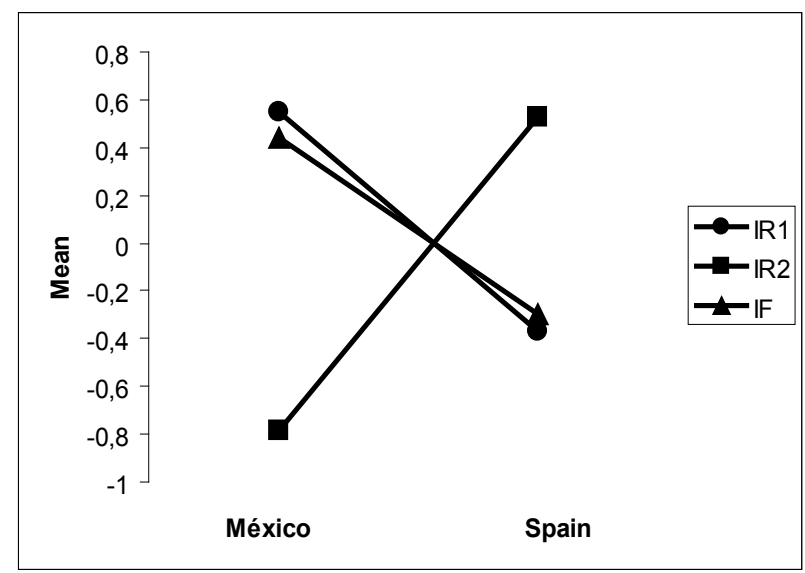

There would clearly seem to be cultural differences in the sense that the Mexican sample presents higher values for the IR1 and IF factors, whereas the Spanish sample scores higher on the IR2 factor. It could be concluded, therefore, that resources are greater in the European sample, while interpersonal relationships and psychic stability are higher in the Mexican sample, perhaps because the social and family values of support and care are more consistently preserved within Mexican culture.

\section{Discussion}

A number of reports regarding schizophrenia have focused, at least partially, on the close relationship between this disease and the concept of quality of life, and as a consequence, the 
HRQLS has become widely used in many empirical studies on measurement and diagnostic processes (Cardoso et al., 2002, Cardoso et al., 2003, Mínguez et al., 2005, Rodríguez et al. 1995 or Simon, et al. 1999). Despite the confirmed internal validity of the HRQLS (factor structure proposed by Scott et al., 2006, convergent and internal consistency), the duality formed by schizophrenia and quality of life is due to a very complex relationship involving several factors such as timing, lack of effective treatment and the side-effects of psychoactive drugs, all of which are common in other disorders. There are also particular and intrinsic features of the illness, such as a lack of disease awareness, disability and social stigma. Special attention should then be paid to comparative transcultural studies with diverse samples which contain information from a particular cultural perspective; however, such studies are not merely instrumental adaptations, because the experience of symptomatology does not appear in patients with a different cultural background.

The results of the present study reveal no significant differences in the HRQLS's total score, probably because both samples behave similarly in most of the components of the disease diagnosis that are related to quality of life. However, when a more detailed analysis of factors is carried out for each group, the Mexican sample presents higher values for the IR1 (Interpersonal Relationships) and IF (Intrapsychic Foundations) factors. Hence, it can be concluded that these aspects of quality of life, i.e. interpersonal relationships and psychic stability, are better preserved in the Mexican sample, a possible explanation to this fact could be due to the stronger presence of social and family values in Mexican culture. In contrast, the Spanish sample scored higher on the IR2 (Instrumental Resources) factor, could be associated with more highly developed social programmes in Spain. Alternatively, it may be that the Spanish subjects have greater functional ability, with a higher level of achievement and satisfaction. We believe that the first explanation is more likely to account for these results.

At all the events, it is worth noting the clearly different internal distribution of scale factors, which suggests a distinct patient profile; however, it does not necessarily mean that these differences reflect a higher or lower overall quality of life in either of the two samples. Obviously, the sample sizes used in this study do not enable any inferences to be drawn as regards the populations, but given that the two samples were matched, it seems reasonable to assume that a superficial evaluation of measurement results would provide a basis for ruling out any profile hidden by the factors. Indeed, the findings would seem to support the introduction of different therapeutic interventions as regards the normalization of daily life in these patients. Our data are heavily based on a more regionalist conception of psychosocial therapeutic intervention for those aspects derived from the relationship between the subject-patient and his/her immediate social context, unlike other studies (Beasley et al., 2006, Borgoñós et al., 1995, Browne 1999, Cardoso et al., 2002 or Mínguez et al., 2005), and they obviously take into account the particular components of the most conventional treatments. In summary, interventions aimed at normalizing everyday life and quality of life in this kind of patient should not be based on general criteria but rather on contextualized criteria; furthermore, they should be monitored via measurements derived from scales such as the HRQLS, whose psychometric efficacy has been demonstrated. Such scales can be used to carry out an exhaustive profile analysis instead of generic evaluations that run the risk of failing to detect clinically relevant details.

\section{References}

Baca, E., Pérez, M.M., Basurte, I., Quintero, F.J., Sevilla, J., Martínez, M., Artes, A., Fernández del Moral, A.L., Jiménez, M.A., \& González de Rivera, J.L. (2008). Patterns of mental health service utilization in a general hospital and outpatient mental health facilities. European Archives of Psychiatry and Clinical Neuroscience, 258, 117-123.

Barcia, D., Morcillo, L., \& Borgoñós, E. (1995). Esquizofrenia. Calidad de vida y formas clínicas. Anales de Psiquiatría, 11(3), 81-87.

Beasley, CM., Sutton, V.K., Taylor, CC., Sethuranam, G., Dossenbach, M., \& Naber, D. (2006). Is quality of life among minimally symptomatic patients with schizophrenia better following withdrawal or continuation of antipsychotic treatment? Journal of Clinical Psychopharmacology, 26 (1), 40-44.

Bentler, P.M., \& Wu, E.J.C. (1995). EQS for Windows. User's Guide. Encino, CA: Multivariate Software Inc.

Bellack, A.S., Morrison R., Wixted, L., \& Mueser, Kt. (1990). An Analysis of Social Competence in Schizophrenia. British Journal of Psychiatry, 156, 809 - 819.

Borgoñós, E., Morcillo, L., \& Barcia, D. (1995). Tratamiento farmacológico y calidad de vida en la esquizofrenia. Revista de Psiquiatría, psicología y Psicosomática, 16 (3), 11-20.

Bow, C.C., Velligan, D.I., Millar, A.L., \& Olsen, J. (1999). Predicting quality of life from symptomatology in schizophrenia at exacerbation and stabilization. Psychiatry Research, 86 (2), 131-142.

Browne, S. (1999). Rehabilitation programmes and quality of life in severe mental illness. International Journal of Social Psychiatry, 45 (4), 302-309.

Bryson, G., Lysaker, P., \& Bell, M. (2002). Quality of life benefits of paid work activity in schizophrenia. Schizophrenia Bulletin, 28 (2), 249-257.

Cardoso, C.S., Bandeira, M., Caiaffa, W.T., \& Fonseca, J.O.P. (2002). Escala de qualidade de vida para pacientes con esquizofrenia (QLS-BR): Adaptação transcultural para o Brasil. Jornal Brasileiro de Psiquiatria, 51 (1), 31-38.

Cardoso, C.S., Caiaffa, W.T., Bandeira, M., Siquiera, A.L., Fonseca, I.K., \& Fonseca, J.O.P. (2003). Qualidades psicométricas de escala de qualidade de vida para pacientes 
con esquizofrenia. Escala QLS-BR. Jornal Brasileiro de Psiquiatria, 52 (3), 211-222.

Ching, F., \& Wan, S.H. (2006). Clinical characteristics and objective living conditions in relation to quality of life among community-based individuals of schizophrenia in Hong Kong. Quality of Life Research, 15, 1459-1469.

Cramer, J.A., Rosenheck, R., Xu, W., Thomas, J., Henderson, W., \& Charney, D.S. (2000). Quality of Life in Schizophrenia: a comparison of instruments. Schizophrenia Bulletin, 26 (3), 659-666.

Franz, M., Lemke, M.R., Meyer, T., Ulferts, J., Puhl, P., \& Snaith, R.P. (1998). German Version of the Snaith-Hamilton Pleasure Scale (SHAPS-D): Assessing anhedonia in schizophrenic and depressive patients. Fortschritte der Neurologie, Psychiatrie, 66 (9), 407-413.

González, E., Alonso, F., Mínguez, L., \& Sanguino, R. (2004). Esquizofrenia: Relación entre déficit cognitivo y calidad de vida. Anales de Psiquiatría, 20 (10), 434-438.

Gourevitch, R., Abbadi, S., \& Guelfi, J.D. (2004). Quality of Life in schizophrenia with and without the deficit syndrome. European Psychiatry, 19 (3), 172-174.

Grant, C. (2000). Social functioning in first and multiepisode schizophrenia. Dissertation Abstracts International: Section B: The Sciences and Engineering, 61 (3-B), 1634.

Guardia, J. (1986). Los Modelos de Ecuaciones Estructurales en el ámbito de la Psicología. Tesis Doctoral no publicada. Barcelona: Universidad de Barcelona.

Heinrichs, D.W., Nalón, T.E., \& Carpenter, W.T. (1984). The Quality of Life Scale: an instrument for rating the schizophrenic deficit syndrome. Schizophrenia Bulletin, 10 (3), 388-398.

Hofstetter, J.R., Lysaker, P.H., \& Mayeda, A.R. (2005). Quality of sleep in patients with schizophrenia is associated with quality of life and coping? BMCV Psychiatry, 5, 13.

Kartsona, A., \& Hilari, K. (2006). Quality of life in aphasia: Greek adaptation of the stroke and aphasia quality of life scale 39 item (SAQOL-39). Europa Medicophysica, 42, 1-9.

Kendall, P.C., \& Sheldrick, C.S. (2000). Normative data for normative comparisons. Journal of Consulting and Clinical, 68 (5), 767-773.

Lee, S.Y. (2006). Structural Equation Model. A Bayesian Approach. New York: Wiley.

Lehman, A.F., Postrado, L.T., \& Rachuba, L.T. (1993). Convergent validation of quality of life assessment for persons with severe mental illnesses. Quality of Life Research, 2 (5), 327-33.

Mínguez, L., González, E., Alonso, F., Sanguino, R.M., \& García, F.J. (2005). Resistencia y tiempo de hospitalización en relación con la calidad de vida de los pacientes esquizofrénicos. Anales de Psiquiatría, 21 (1), 39-44.

Möller, H.J. (2006). Is there evidence for negative effects of antidepressants on suicidability in depressive patients?
European Archives of Psychiatry and Clinical Neuroscience, 256, 476-496.

Morcillo, L., Barcia, D., \& Borgoñós, E. (1995). Esquizofrenia: calidad de vida y años de evolución. Actas Luso-Españolas de Psiquiatría, 23 (6), 293-298.

Phillips, G.A., Van Brunt, D.L., Roychowdhury, S.M., Xu, W., \& Naber, D. (2006). The relationship between quality of life and clinical efficacy from a randomized trial to comparing olanzapine and ziprasidone. Journal of Clinical Psychiatry, 67 (9), 1397-1403.

Pol, E., Neipp, R.M., \& Rodríguez, M. (2000). Calidad de vida en personas con esquizofrenias en un Centro de Día. Psiquis, 21 (1), 48-54.

Rodríguez, A., Rodríguez, M.A., Jarne, A., Miarons, R., Grau, A., \& Soler, R. (1995). Adaptación y análisis factorial de la escala de Calidad de Vida en la Esquizofrenia. Revista de Psicología General y Aplicada, 48, 353-364.

Scott, N.W., Fayers, P.M., Aaronson, N-K., Bottomley, A., de Graeff, A., Groenvold, M., Koller, M., Petersen, M.A., \& Sprangers, M.A.G. (2006). Comparing translations of the EORTC QLQ-C30 using differential item functioning analyses. Quality of Life Research, 15, 1119 - 1120.

Simon, S., Guelfi, J.D., \& Ginestet, D. (1999). Psychometric qualities of the French version of the Heinrichs quality of life rating scale. European Psychiatry, 14 (7), 386-391.

Whitty, P., Browne, S., Clarke, M., McTigue, P., Kinsella, T., Larkin, C., \& O'Callaghan, E. (2004). Systematic comparison of subjective and objective measures of quality of life at 4-year follow-up subsequent to a first episode of psychosis. Journal of Nervous and Mental Disease, 192 (12), 805-809.

Received February 2, 2009 Accepted June 9, 2009 